\title{
Comparative feeding and nutrition in captive, non-human primates
}

\author{
BY G. J. KING* \\ Freund Nutritional Research Laboratory, Wildlife Preservation Trust, Jersey, Channel Islands
}

(Received I9 May 1977 - Accepted I February 1978)

I. Food intake studies were carried out on three groups of captive primates (anthropoid apes (Pongidae), lemurs (Lemuridae) and marmosets (Callitrichidae).

2. Determination and analysis of the nutrient intakes were carried out by calculations based on food tables. The results from all groups were compared.

3. Marmosets were found to have higher intakes of energy and many other nutrients than the apes and lemurs.

4. The results suggest that there is a tendency towards over use of dietary supplements and foods of higher nutrient density for captive primates.

During the last 3 years, a series of food intake studies have been carried out on three groups of primates which are maintained and have reproduced at the Wildlife Preservation Trust, Jersey. The main purpose was to analyse the nutrient intakes, thereby identifying any obvious deficiencies or anomalies in the diets. Secondly, the information cculd be used in the formulation of alternative diets, should changes in composition be required due to failures in supply or by financial pressures. Comparisons of food and nutrient intakes between the groups were made to identify any similarities or differences in the nutrition of these primates.

\section{EXPERIMENTAL}

Animals. Results from a total of thirty-seven non-pregnant, non-lactating adult animals were obtained; details of the animals studied are given in Table I. Almost all the animals were kept as male-female pairs, and in the lemurs and marmosets in particular, total food intakes from each pair were averaged to give the intake per animal. The ape results were measured singly except for one pair of two females.

Body-weights of the lemurs and marmosets were measured at the ends of the studies, using a platform supported on a domestic spring balance of $5 \mathrm{~kg}$ capacity and baited with food. Some of the marmosets were captured and weighed on a triple-beam balance. The body-weight of one orang-utan was obtained during anaesthesia for an operation but all other ape weights were estimates averaged from those given by staff working with the animals. Changes in body-weight were not determined.

\section{Diets}

Methods. Food intakes were measured by weighing the amounts offered to the animals, followed by collection and re-weighing of any residue. Allowances for weight loss due to evaporation were made as indicated by controls. Nutrient intakes were then calculated from food tables in McCance \& Widdowson (1960), Documenta Geigy (1970), Platt (1962) and Burton (1976) and from the declared analyses of food manufacturers.

Direct vitamin and mineral supplementation was used in the diets of the marmosets and apes. With the marmosets, this took the form of a multi-vitamin/mineral powder sprinkled on the food (Vitetrin; E. R. Squibb and Son, Twickenham, Middlesex). The apes received

\footnotetext{
* Present address: Staddon House, North Tawton, Devon EX20 2DP.
} 
Table I. Details of animals studied to provide information for comparative nutritional assessment of three primate groups

\begin{tabular}{clcc}
\multicolumn{1}{c}{ Group } & \multicolumn{1}{c}{ Species } & No. adult $\sigma^{*}$ & No. adult \\
(1) Apes (Pongidae) & Gorilla gorilla gorilla & I & 2 \\
& Pongo pongo pygmaeus & I & I \\
& P. pongo abelii & I & I \\
(2) Lemurs (Lemuridae) & Lemur fulvus mayottensis & 2 & 2 \\
& L. mongoz mongoz & 2 & 3 \\
& L. catta & 2 & 2 \\
(3) Marmosets (Callitrichidae) & Callithrix jacchus jacchus & 3 & 3 \\
& C. argentata & 1 & 1 \\
& Saguinus midas & 2 & 2 \\
Total no. of animals & S. oedipus & 3 & 2 \\
& & 18 & 19
\end{tabular}

two types of proprietary liquid vitamin preparation, either directly from a spoon, or mixed in the drink (Orovite, Bencard, Brentford, Middlesex and Adexolin, Glaxo Laboratories Ltd, Greenford, Middlesex). All three groups of primates received a cyanocobalamin supplement in their drink twice weekly (Cytacon, Glaxo Laboratories Ltd).

For the purposes of comparison, the resulting intakes of dry matter (DM), energy, protein, fat, retinol, cholecalciferol and calcium and phosphorus were used.

Statistical analysis. Student's $t$ test was used to determine the significance of differences between intakes of the three groups. Double logarithmic regression lines were calculated by the method of least squares.

\section{RESULTS}

Diets. The diets included three groups of components. First, primate pellets (BP Nutrition Ltd, Witham, Essex, and Nitrovit Ltd, Thirsk, Yorkshire), or a mixture based upon the two types of pellet in the instance of the lemurs. The nutrients provided by any vitamin-mineral supplementation were included with the pellets. The second group of components was the plant products, mainly fresh fruits and vegetables, dried fruits and brown bread, whilst the third group of components was animal products such as milk, eggs, yoghurt, fresh and tinned meats (Spratts Patent Ltd, Barking, Essex), and insects (mealworms (Tenebrio molitor)) and crickets (Gryllus sp.).

Fig. I shows the relative intakes of $D M$, energy, protein and fat supplied by each dietary component group for the three primate groups. Total DM of the diets was between 230 and $270 \mathrm{~g} / \mathrm{kg}$ fresh weight. Between 12 and $22 \%$ of this DM was supplied by the primate pellets, including any supplements, $63-77 \%$ by plant products and $7-16 \%$ by animal products. Vitamin supplementation alone accounted for less than $0.5 \%$ of any diet.

The proportions of energy supplied by each dietary component group were similar (Fig. I). This indicated a similarity in energy density in the diets of all three primate groups; energy density of the DM was between 15.5 and $16 \cdot 3 \mathrm{~kJ} / \mathrm{g}$.

Primate pellets supplied $28-47 \%$ of the protein, plant products between 35 and $40 \%$ and animal products $18-35 \%$ (Fig. I), values which reflect the higher value for protein: energy of the pellets and animal products. Soya beans (Glycine sp.), cereals and fish meal were the main sources of protein in the primate pellet, and the declared amino acid analysis of BP Nutrition Ltd was used. Similarly, the declared fatty acid analysis was used to determine the contribution of the primate pellets to the fat intakes. Animal products were relatively more important sources of dietary fat, particularly in the lemur and marmoset diets where they supplied 45 and $31 \%$ of fat intakes respectively. The large quantities of fat supplied by the 


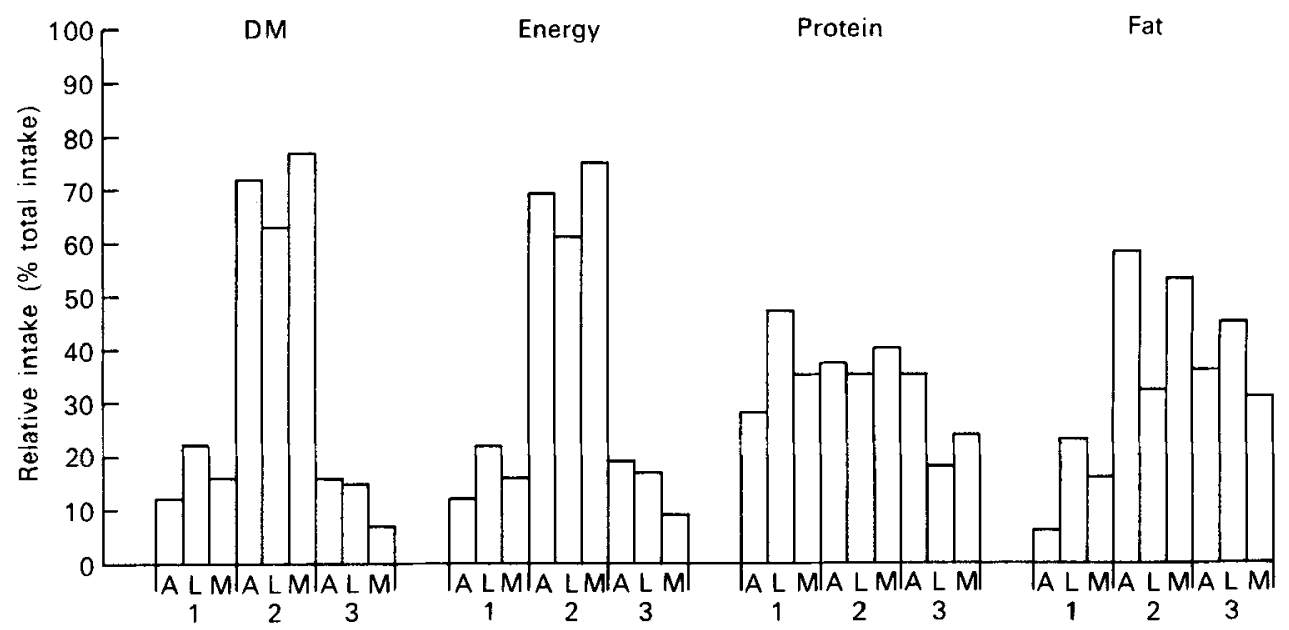

Fig. I. Relative intakes (\% total intake) of dry matter (DM), energy, protein and fat of three primate groups, apes (Pongidae) (A), Lemurs (Lemuridae) (L), and marmosets (Callitrichidae) (M) derived from primate pellets (I), plant products (2) and animal producis (3) (for details see p. 56)

plant products were accounted for by the inclusion of peanuts (Arachis hypogaea), sunflower seeds (Helianthus sp.) and, more importantly in the ape diets, coconut (Cocos nucifera). As a result, plant products provided between 32 and $58 \%$ of the total fat (Fig. I).

DM and energy intakes. Body-weights were taken as the basis of the comparative nutritional assessment of food intakes, and ranged from a $300 \mathrm{~g}$ marmoset to an estimated $150 \mathrm{~kg}$ male gorilla (Gorilla gorilla gorilla). The average weights for animals in each group are given in Table 2.

Voluntary food intake (VFI) as DM ( $\mathrm{g} / \mathrm{kg}$ body-weight) averaged 9 in the apes, 22 in the lemurs and 52 in the marmosets (Table 2). A double logarithmic regression analysis of DM intake $v$. body-weight indicated that intake varied with body-weight to the power 0.67 ( $r 0.99$ ), with a mean intake for all species of $34 \mathrm{~g} / \mathrm{kg}$ body-weight $\mathrm{t}^{0 \cdot 67}$.

By the same allometric method, VFI as energy was found to vary with body-weight to the power $0.68(r 0.99)$, with a mean value for all species of $540 \mathrm{~kJ} / \mathrm{kg}$ body-weight ${ }^{0.68}$. Considering the wide variations in both body-weight and food intakes in the three primate groups, these values for body-weight were not considered to be significantly different to the general value for metabolic body-weight of $\mathrm{kg}^{\mathbf{0} \cdot 75}$ (Kleiber, 196I).

Using Kleiber's value, over-all mean energy intake was almost $500 \mathrm{~kJ} / \mathrm{kg}$ body-weight ${ }^{0 \cdot 75}$, with a coefficient of variation (CV) of 0.3 . This suggested a range of possible energy intakes of from 200 to $790 \mathrm{~kJ} / \mathrm{kg}$ body-weight $\mathrm{t}^{0.75}$. The high $\mathrm{CV}$ could be explained by examination of the mean energy intakes $\left(\mathrm{kJ} / \mathrm{kg}\right.$ body-weight ${ }^{0.75}$ ) for each group (Table 2 ): apes $4 \mathrm{I} 8$, lemurs 409 , marmosets 677 . In each instance, the $\mathrm{CV}$ for the group means were below that for the interspecific mean.

Basal metabolic rate (BMR) is generally accepted to be $290 \mathrm{~kJ} / \mathrm{kg}$ body-weight ${ }^{0.75}$ (Kleiber, 196I). Energy intakes for both the apes and lemurs were approximately I $4 \times$ BMR (Table 2 ), and were not significantly different from each other $(P<0.05)$. BMR for marmosets has been determined as approximately $350 \mathrm{~kJ} / \mathrm{kg}$ body-weight ${ }^{0 \cdot 75}$ (Rivers \& Frankel, personal communication). Observed energy intake for marmosets was almost $2 \times$ BMR (Table 2), and was significantly higher than the intakes of the apes and lemurs $(P<0.05)$.

Protein intake. Dietary protein supplied between 9.5 and $13 \%$ of the energy intakes, close to the usual levels of 10-12\% found in human diets. Actual intakes ( $\mathrm{g} / \mathrm{kg}$ body-weight) 
Table 2. Daily dry matter (DM) and energy intakes in three groups of primates, apes (Pongidae), lemurs (Lemuridae) and marmosets (Callitrichidae)*

(Mean values with their standard errors; ranges and no. of observations are given in parentheses)

\begin{tabular}{|c|c|c|c|}
\hline & Apes & Lemurs & Marmosets \\
\hline & Mean & Mean & Mean \\
\hline $\begin{array}{l}\text { Body-wt (W) (kg) } \\
\quad \text { Range }\end{array}$ & $\begin{array}{l}76 \cdot 5 \\
38-150(6)\end{array}$ & $\begin{array}{l}2.5 \\
1 \cdot 7-3.3(13)\end{array}$ & $\begin{array}{ll}0.44 & 0.02 \\
0.3-0.57(17)\end{array}$ \\
\hline $\begin{array}{l}\text { Voluntary food intake (DM) (g/kg W) } \\
\text { Range }\end{array}$ & $\begin{array}{l}8 \cdot 8 \quad 0.2 \\
7 \cdot 5-10 \cdot 6(12)\end{array}$ & $\begin{array}{l}22 \cdot 0 \quad I \cdot 0 \\
16 \cdot 8-25 \cdot 9(8)\end{array}$ & $\begin{array}{l}52 \cdot 0 \quad 3 \cdot 5 \\
35 \cdot 3-64 \cdot 5(9)\end{array}$ \\
\hline $\begin{array}{l}\text { Energy intake }\left(\mathrm{kJ} / \mathrm{W}^{0 \cdot 75}\right) \\
\text { Range }\end{array}$ & $\begin{array}{l}418 \quad I I \cdot 5 \\
368-494(I 2)\end{array}$ & $\begin{array}{l}409 \\
36 I-5 I 4(8)\end{array}$ & $\begin{array}{l}677 \quad 47 \cdot 4 \\
573-1067(9)\end{array}$ \\
\hline Coefficient of variation (CV) & 0.09 & 0.13 & 0.21 \\
\hline $\begin{array}{l}\text { Assumed basal metabolic rate (BMR) } \dagger \\
\left(\mathrm{kJ} / \mathrm{W}^{0.75}\right)\end{array}$ & 290 & 290 & 350 \\
\hline Energy intake $\div$ BMR & $1 \cdot 4$ & $1 \cdot 4$ & I.9 \\
\hline Interspecific mean energy intake $\left(\mathrm{kJ} / \mathrm{W}^{0.75}\right)$ & $496 \pm 27 \cdot 8$ & CV 0.3 & \\
\hline
\end{tabular}

* For details, see Table I.

$\dagger$ BMR is the energy requirement of the fasting body at rest, at room temperature (approximately $20^{\circ}$ ).

were $I \cdot I$ in apes, $I \cdot 9$ in lemurs and 6.4 in marmosets. All intakes were significantly different $(P<0.05)$ (Table 3$)$.

The amino acid score, or net protein utilization (standardized) (NPU) of the dietary protein was calculated relative to the reference pattern of amino acids for humans (FAO/WHO, 1973). NPU of the diets were between 0.77 and 0.83 (Table 3), with sulphur amino acids limiting in the apes and lemurs, and threonine limiting in the marmosets.

Fat intake. Intakes of fat varied from $20 \%$ of the energy in the apes to only $8.5 \%$ in the lemurs (Table 4). The sources of dietary fat are indicated in Fig. I. By calculation, values for saturated fatty acid: polyunsaturated fatty acid (PUFA) were between $2.5: 1$ in the apes and $0.7: I$ in the marmosets. Expressed another way, the amount of the total energy intake derived from PUFA was between 3 and $5 \%$ (Table 4 ).

In the ape and lemur diets, saturated fats from milk supplied 30 and $45 \%$ of the total fat intake respectively, while in the ape diet coconut supplied a further $12 \%$ as saturated fat, even though this was not a daily item in the diet. In the marmoset diet, where milk was a minor component, saturated fats from all animal products (mostly canned meat and eggs) accounted for approximately $10 \%$ of the total fat. In all three groups, plant products (mainly fresh fruits and vegetables) were the major sources of PUFA, supplying between I I and $19 \%$ of the total fat intakes.

Retinol intake. Intakes of retinol were corrected to allow for a $50 \%$ efficiency of conversion to vitamin A activity of the $\beta$-carotenes from plant sources. This may be an underestimate for species which are primarily vegetarian.

Actual intakes were $48 \mu \mathrm{g} / \mathrm{kg}$ body-weight in the apes and lemurs, increasing to the significantly higher value $(P<0.001)$, of $171 \mu \mathrm{g} / \mathrm{kg}$ body-weight in the marmosets. Dietary levels reflected these intakes, bearing in mind the high food intakes per unit body-weight exhibited by the low body-weight species such as the marmosets (Table 5).

Preformed retinol from primate pellets and vitamin supplements, and from animal products, accounted for $29 \%$ of the intake in the apes, $50 \%$ in the lemurs, and $75 \%$ in the marmosets; the remaining amounts were derived from the precursor $\beta$-carotenes in plant products. 
Table 3. Daily protein intakes and calculated requirements for three groups of primates, apes (Pongidae), lemurs (Lemuridae) and Marmosets (Callitrichidae)*

(Mean values with their standard errors; no. of observations/group is given in parentheses)

Protein : energy

Protein intake $(\mathrm{g} / \mathrm{kg}$ body-wt)

Calculated NPU $†$ of diets

Calculated 'safe' level of protein intake $(\mathrm{g} / \mathrm{kg}$ body-wt)

Actual intake (\% of requirement)

\begin{tabular}{|c|c|c|c|c|c|}
\hline \multicolumn{2}{|c|}{ Apes (12) } & \multicolumn{2}{|c|}{ Lemurs (8) } & \multicolumn{2}{|c|}{ Marmosets (9) } \\
\hline Mean & SE & Mean & SE & Mean & SE \\
\hline $12 \cdot 6$ & 0.33 & 9.5 & 0.34 & $13 \cdot 1$ & 0.37 \\
\hline $1 \cdot 09$ & 0.03 & $1 \cdot 93$ & 0.08 & $6 \cdot 4$ & 0.43 \\
\hline \multicolumn{2}{|c|}{0.8} & \multicolumn{2}{|c|}{0.77} & \multicolumn{2}{|c|}{0.83} \\
\hline \multicolumn{2}{|c|}{0.62} & \multicolumn{2}{|c|}{$1 \cdot 5$} & \multicolumn{2}{|c|}{$2 \cdot 6$} \\
\hline \multicolumn{2}{|c|}{176} & \multicolumn{2}{|c|}{129} & \multicolumn{2}{|c|}{246} \\
\hline
\end{tabular}

* For details, see Table $\mathrm{I}$.

+ NPU, net protein utilization, represents the dietary amino acid score relative to the reference pattern of amino acids for humans (FAO/WHO, 1973).

Table 4. Daily fat intakes and analysis of dietary fat composition in three groups of primates, apes (Pongidae), lemurs (Lemuridae) and marmosets (Callitrichidae)*

(Mean values with their standard errors; no. of observations/group is given in parentheses)

Fat:energy

PUFA: energy

Saturated fats (\% total fat)

PUFA ( $\%$ total fat)

Saturated fat:PUFA

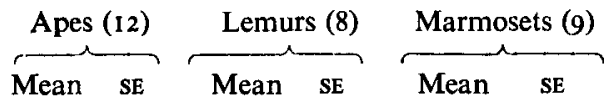

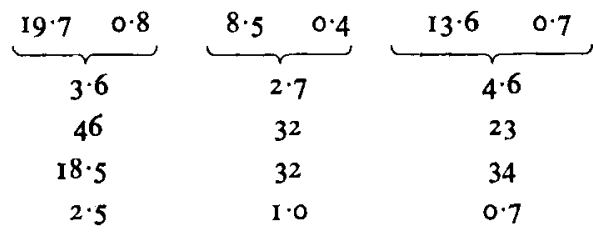

PUFA, polyunsaturated fatty acids.

* For details, see Table I.

Cholecalciferol intake. Relatively low levels of intake of cholecalciferol were found in the apes and lemurs compared with the high intakes of the marmosets. Expressed in terms of metabolic body-weight, intakes for the apes and lemurs were 0.5 and $0.55 \mu \mathrm{g} / \mathrm{kg}$ bodyweight ${ }^{0.75}$ respectively, and were not significantly different $(P<0.05)$, while the intake of the marmosets was $2.4 \mu \mathrm{g} / \mathrm{kg}$ body-weight ${ }^{0.75}$ which was significantly higher than the other groups $(P<0.001)$ (Table 5$)$.

Dietary levels again reflected these intakes, as was found with the retinol intakes, and varied from approximately $20 \mu \mathrm{g} / \mathrm{kg} \mathrm{DM}$ in the apes and lemurs to $55 \mu \mathrm{g} / \mathrm{kg}$ DM in the marmosets. Of the dietary cholecalciferol, $84-99 \%$ was supplied by the primate pellets and supplements; the remaining 16 and $\mathrm{I} \%$ in the apes and lemurs respectively were from milk products, and the remaining $10 \%$ in the marmosets from eggs and canned carnivore diet.

$\mathrm{Ca}$ and $\mathrm{P}$ intakes. Levels of $\mathrm{Ca}$ and $\mathrm{P}$ intakes were of concern considering the large quantities of fruits and vegetables in the diets. A recommended value for $\mathrm{Ca}: \mathrm{P}$ is between 2: I and I : I depending on age ((US) Food and Nutrition Board, I968); in all three primate diets studied here the value was close to unity (Table 6). Quantitively, intakes (mg/kg 
Table 5. Daily retinol and cholecalciferol intakes for three groups of primates, apes (Pongidae), lemurs (Lemuridae) and marmosets (Callitrichidae)*

(Mean values with their standard errors; no. of observations/group is given in parentheses)

\begin{tabular}{|c|c|c|c|c|c|c|}
\hline \multirow[b]{2}{*}{ Retinol: } & \multicolumn{2}{|c|}{ Apes (12) } & \multicolumn{2}{|c|}{ Lemurs (8) } & \multicolumn{2}{|c|}{ Marmosets (9) } \\
\hline & Mean & $\mathbf{S E}$ & Mean & SE & Mean & SE \\
\hline $\begin{array}{l}\mu \mathrm{g} / \mathrm{kg} \text { body-wt } \\
\mu \mathrm{g} / \mathrm{kg} \text { dietary } \mathrm{DM}\end{array}$ & $\begin{array}{l}47 \cdot 2 \\
5380\end{array}$ & $\begin{array}{r}1 \cdot 7 \\
220\end{array}$ & $\begin{array}{l}48 \cdot I \\
2190\end{array}$ & $\begin{array}{l}2 \cdot 1 \\
165\end{array}$ & $\begin{array}{l}170 \cdot 9 \\
3330\end{array}$ & $\begin{array}{l}14 \cdot \text { I } \\
204\end{array}$ \\
\hline $\begin{array}{l}\text { Cholecalciferol: } \\
\mu \mathrm{g} / \mathrm{kg} \text { body-wt } \\
\mu \mathrm{g} / \mathrm{kg} \text { body-wt } \mathrm{t}^{0.75} \\
\mu \mathrm{g} / \mathrm{kg} \text { dietary } \mathrm{DM}\end{array}$ & $\begin{array}{l}0.2 \\
0.5 \\
20\end{array}$ & $\begin{array}{l}0.01 \\
0.03 \\
1.2\end{array}$ & $\begin{array}{l}0.4 \\
0.55 \\
19.5\end{array}$ & $\begin{array}{l}0.06 \\
0.08 \\
2 \cdot 5\end{array}$ & $\begin{array}{l}2 \cdot 8 \\
2 \cdot 4 \\
55\end{array}$ & $\begin{array}{l}0.4 \\
0.3 \\
6.3\end{array}$ \\
\hline
\end{tabular}

Table 6. Daily calcium and phosphorus intakes for three groups of primates, apes (Pongidae), lemurs (Lemuridae) and marmosets (Callitrichidae)*

(Mean values with their standard errors; no. of observations/group is given in parentheses)

\begin{tabular}{|c|c|c|c|c|c|c|}
\hline & \multicolumn{2}{|c|}{ Apes (12) } & \multicolumn{2}{|c|}{ Lemurs (8) } & \multicolumn{2}{|c|}{ Marmosets (9) } \\
\hline & Mean & SE & Mean & $\mathbf{S E}$ & Mean & SE \\
\hline $\mathrm{Ca}: \mathrm{P}$ & $I \cdot 19$ & 0.13 & 0.98 & 0.02 & 1.07 & 0.03 \\
\hline $\mathrm{Ca}(\mathrm{g} / \mathrm{kg}$ dietary $\mathrm{DM})$ & $4 \cdot 2$ & 0.2 & $2 \cdot 7$ & 0.08 & $4 \cdot 0$ & 0.2 \\
\hline Ca intake (mg/kg body-wt) & $37 \cdot \mathrm{I}$ & $\mathrm{I} \cdot 7$ & $59 \cdot 3$ & $2 \cdot 4$ & 205.8 & $18 \cdot 3$ \\
\hline$P(g / k g$ dietary $D M)$ & $3 \cdot 5$ & 0.1 & $2 \cdot 7$ & 0.06 & $3 \cdot 7$ & 0.2 \\
\hline $\mathrm{P}$ intake (mg/kg body-wt) & $3 I \cdot 2$ & $1 \cdot 2$ & $60 \cdot 8$ & $2 \cdot 3$ & 193.8 & 14.4 \\
\hline
\end{tabular}

body-weight) were approximately $30-40$ in the apes, 60 in the lemurs and close to 200 in the marmosets.

\section{DISCUSSION}

The primate diets represented in this paper have been devised over many years of continuous review and improvement. One striking feature was the relatively low proportion of foods of animal origin in the diet provided for the marmosets. These animals are of a more carnivorous nature than either the apes or lemurs in the wild (Deinhardt, 1970). This was due to the large quantities of milk used in the diets of those latter animals to improve protein and Ca contents.

Primate pellets are produced commercially as complete diets for a range of non-human primates. In the Wildlife Preservation Trust, Jersey, they are used as a protein-vitaminmineral complement for diets based predominantly on fresh fruits and vegetables.

Supplementation with vitamin or vitamin-mineral preparations is used in zoos to correct or treat specific conditions or illnesses; these supplements then tend to become included into maintenance diets with the result that high intakes of vitamins, often the fat-soluble vitamins, occur. Even if this is not actually harmful, it almost certainly represents a waste of money.

Marmosets were found to be relatively hyperphagic compared with the other two primate groups studied, notably in terms of DM intake. This may help to explain certain anomalies in their nutrition, such as the high-protein intake discussed below.

The energy intake of marmosets given in Table $2(2 \times$ BMR $)$ is based on the value for BMR 
determined by Rivers \& Frankel (personal communication). This value is approximately $20 \%$ higher than the general value of Kleiber (196I), and tends to mask the relatively higher intakes of energy by the marmosets. In terms of the Kleiber (I96I) value for BMR $(290 \mathrm{~kJ} / \mathrm{kg}$ body-weight $\mathrm{t}^{0.25}$ ), the energy intakes of the marmosets would be approximately $2 \cdot 3 \times \mathrm{BMR}$. However, even this value is not remarkable for an animal as active as the marmoset.

Assuming obligatory nitrogen losses from the body to be the same as those for humans at $0.48 \mathrm{mg} / \mathrm{basal} \mathrm{kJ}$ (FAO/WHO, 1973), and including the suggested allowances for $\mathrm{N}$ balance, individual variation, and an NPU of 0.80 , predicted safe levels of protein intake were $6.2 \mathrm{mg} /$ basal $\mathrm{kJ}$. Converted into values per unit of body-weight using the values for BMR in Table 2, protein requirements $(\mathrm{g} / \mathrm{kg}$ body-weight) for the apes were calculated to be 0.62 , for the lemurs $1 \cdot 5$, and for the marmosets $2 \cdot 6$. The observed intakes in Table 3 were 180 , I 30 and $250 \%$ of the calculated requirements respectively.

A high-protein requirement has been traditionally associated with marmosets. High intakes are bound to occur with high intakes of a diet with a high value for protein:energy. Whilst increased food intake may have occurred to compensate for any amino acid deficiency in the diet, this did not appear to be the case. Arbitrarily halving the NPU of the diet to 0.4 indicated that marmosets would still be consuming $180 \%$ of their calculated protein requirement.

No recommended levels of fat intake were known, although Burton (I976) comments that diets of Western populations may contain up to $40 \%$ of the energy as fat, while in underdeveloped countries the corresponding figure may be only $6-10 \%$. These latter values may be taken to represent the probable fat content of a mainly vegetarian primate diet in the wild, such as that eaten by the apes. Minimal intakes of essential fatty acids (EFA) are said to be I-2 \% of total energy intake for non-human primates (Portman, I970), and while the actual levels of EFA in these diets were not determined, total PUFA intakes of 3-5\% of total energy suggest that EFA deficiencies are unlikely. However, the extent of saturation observed in the ape diet gave cause for concern, particularly since these animals are considered to be predominantly, if not exclusively, vegetarian, and would have little adaptation for diets containing high levels of saturated fats. Atherosclerosis is known to occur in a wide variety of non-human primates fed on atherogenic diets (Strong, 1976), and has been recorded in the Pongidae (Ratcliffe \& Cronin, 1958; Stout \& Lemmon, 1969). As a result of these studies, whole milk has been removed from the ape diets, and replaced by reconstituted dried, skimmed milk.

Requirements for retinol are proportional to body-weight and Brody (I945) suggested minimal interspecific intakes of approximately $6 \mu \mathrm{g} / \mathrm{kg}$ body-weight. The FAO/WHO (1967) recommended level of human intake is approximately $12 \mu \mathrm{g} / \mathrm{kg}$ body-weight, which is $25 \%$ of the intakes in the apes and lemurs, and only $7 \%$ of the marmoset intakes.

Dietary intake of retinol $(\mu \mathrm{g} / \mathrm{kg}$ body-weight) in marmosets was 3.6 times higher than in the apes. This illustrated the problem of including standard levels of certain nutrients, such as retinol, in commercially prepared diets to be used for a range of primates. Species of low body-weight will consume higher levels of nutrients per unit body-weight, a fact of concern particularly with regard to the fat-soluble vitamins.

Cholecalciferol has been an emotive subject in primate nutrition for some years, particularly since 'New World' monkeys were shown to have a specific, and apparently very high, requirement for cholecalciferol (Hunt, Garcia \& Hegsted, 1967). Adult humans are said to require little or no dietary vitamin $\mathrm{D}$ under maintenance, while pregnant and lactating women are recommended to consume $10 \mu \mathrm{g} / \mathrm{d}$ ((US) Food and Nutrition Board, 1968). This is equivalent to approximately $0.5 \mu \mathrm{g} / \mathrm{kg}$ body-weight $\mathrm{t}^{0.75}$, the same level found in the ape and lemur diets discussed earlier, while the marmosets consumed almost five times as much. Previous practices of dosing marmosets with up to $12.5 \mu \mathrm{g}$ cholecalciferol/animal per $\mathrm{d}$ will have resulted in daily intakes of over $25 \mu \mathrm{g} / \mathrm{kg}$ body-weight $t^{0.75}$. While this is below the toxic 
limits of approximately $70-200 \mu \mathrm{g} / \mathrm{kg}$ body-weight ${ }^{0.75}$ in humans (Documenta Geigy, 1970) removal of the animals from indoor accommodation to caging with outdoor areas provided the potential for cholecalciferol production from exposure to ultra-violet radiation. A fatal wasting disease of marmosets has been recorded at the Wildlife Preservation Trust, Jersey, which may be related to cholecalciferol overdosing resulting from the use of direct cholecalciferol supplementation in conjunction with normal production afforded by exposure to ultraviolet radiation (King, I977).

With diets based mainly on fruits and vegetables, maintenance of adequate values for $\mathrm{Ca}: \mathrm{P}$ was of concern. High intakes of $\mathrm{P}$ from plants, as well as meat and insects, were compensated for by intakes of $\mathrm{Ca}$ from the pellets, milk and citrus fruits. Although the diets of all three primate groups studied had similar values for $\mathrm{Ca}: \mathrm{P}$ and concentrations, intakes per unit body-weight were relatively higher in species of low body-weight.

In conclusion, it may be said that the nutrition of zoo animals, including primates, has progressed a great deal in recent years, resulting in reduced mortality and improved productivity (see Ratcliffe, I966). It is felt that some of the nutritional problems now occurring may be due not so much to malnutrition as to the tendency towards 'overnutrition', resulting from attempts to ensure the best possible diets for captive non-human primates in the absence of any real knowledge as to their true nutritional needs.

The author would like to thank Mr J. P. W. Rivers of the Nuffield Institute of Comparative Medicine, The Zoological Society of London, Regents Park, London, for his help and advice in the preparation of this work.

\section{REFERENCES}

Brody, S. (1945). Bioenergetics and Growth. New York: Hafner Press.

Burton, B. J. (1976). Human Nutrition, 3rd ed. New York and London: McGraw-Hill.

Deinhardt, F. (1970). In Feeding and Nutrition of Non-Human Primates [R. S. Harris, editor]. London and New York: Academic Press.

Documenta Geigy (1970). In Scientific Tables [K. Diem \& C. Lentner, editors]. Macclesfield, UK: Geigy Pharmaceuticals.

FAO/WHO (1967). WHO tech. Rep. Ser. no. 362.

FAO/WHO (1973). WHO tech. Rep. Ser. no. 522.

Food and Nutrition Board (1968). Publs natl Res. Coun. no. 1694.

Hunt, R. D., Garcia, F. G. \& Hegsted, D. M. (1967). Lab. Anim. Care 17, 222.

King, G. J. (1977). Ann. Rep. Jersey Wildl. Pres, Trust 8, 97.

Kleiber, M. (1961). The Fire of Life; an Introduction to Animal Energetics. New York: Wiley.

McCance, R. A. \& Widdowson, E. M. (1960). Spec. Rep. Ser. med. Res. Coun. no. 297.

Platt, B. S. (1962). Spec. Rep. Ser. med. Res. Coun. no. 302.

Portman, O. W. (1970). In Feeding and Nutrition of Non-Human Primates [R. S. Harris, editor]. London and New York: Academic Press.

Ratcliffe, H. (1966). Int. Zoo Yearbook 6, 4.

Ratcliffe, H. L. \& Cronin, M. T. I. (1958). Circulation 18, $4 \mathrm{I}$.

Stout, C. \& Lemmon, W. B. (1969). Exp. Molec. Pathol. 10, 312.

Strong, J. P. (1976). Primates in Medicine 9, I. 